University of Nebraska - Lincoln

DigitalCommons@University of Nebraska - Lincoln

6-17-2015

\title{
Penghou, a new genus of flea beetles from China (Coleoptera: Chrysomelidae: Galerucinae: Alticini)
}

Yong-Ying Ruan

Alexander S. Konstantinov

Kaniyarikkal Divakaran Prathapan

Si-Qin Ge

Xing-Ke Yang

Follow this and additional works at: https://digitalcommons.unl.edu/usdaarsfacpub

This Article is brought to you for free and open access by the U.S. Department of Agriculture: Agricultural Research Service, Lincoln, Nebraska at DigitalCommons@University of Nebraska - Lincoln. It has been accepted for inclusion in Publications from USDA-ARS / UNL Faculty by an authorized administrator of DigitalCommons@University of Nebraska - Lincoln. 
http://dx.doi.org/10.11646/zootaxa.3973.2.5

http://zoobank.org/urn:lsid:zoobank.org:pub:5851DACD-8AD3-44AB-B289-8F7368E90B8E

\title{
Penghou, a new genus of flea beetles from China (Coleoptera: Chrysomelidae: Galerucinae: Alticini)
}

\author{
YONG-YING RUAN ${ }^{1,3}$, ALEXANDER S. KONSTANTINOV ${ }^{2,5}$, K. D. PRATHAPAN ${ }^{4}$, \\ SI-QIN GE ${ }^{1} \&$ XING-KE YANG ${ }^{1,5}$ \\ ${ }^{1}$ Key Laboratory of Zoological Systematics and Evolution, Institute of Zoology, Chinese Academy of Sciences, Beijing 100101, China \\ ${ }^{2}$ Systematic Entomology Laboratory, USDA, ARS, Washington DC, USA \\ ${ }^{3}$ University of Chinese Academy of Sciences, Beijing, 100039, China \\ ${ }^{4}$ Department of Entomology, Kerala Agricultural University, Vellayani P.O., Trivandrum -695 522, Kerala, INDIA. \\ E-mail: prathapankd@gmail.com \\ ${ }^{5}$ Corresponding authors.E-mail:yangxk@ioz.ac.cn; alex.konstantinov@ars.usda.gov
}

\begin{abstract}
A new genus (Penghou) with a single new species (P. yulongshan) from Yunnan Province in China is described and illustrated. It is compared to Hespera Weise, Hesperomorpha Ogloblin, Laotzeus Chen, Luperomorpha Weise, Mandarella Duvivier, Omeiana Chen, Stenoluperus Ogloblin and Taiwanohespera Kimoto.
\end{abstract}

Key words: new genus, new species, flea beetle, Alticinae, China, Yunnan

\section{Introduction}

The Chinese fauna of flea beetles with about 100 genera and 1200 species, is one of the largest and most complex among regional Asian faunas. Recent flea beetle field investigations revealed a number of new taxa (e.g. Cangshanaltica Konstantinov et al. 2013) (Konstantinov \& Lingafelter 2002, Konstantinov et al. 2011, 2013, Ruan et al. 2014, Sprecher-Uebersax et al. 2009). Here we describe a previously unknown genus of flea beetles. Based on morphological characters, particularly those of the elytra and legs, it resembles genera close to Luperomorpha Weise and Hespera Weise. A recent, mostly molecular, phylogenetic study (Ge et al. 2012) placed these genera deep within Galerucini. However, their phylogenetic position as well as relationships of Alticini and Galerucini in general remains unclear, mostly due to a great species diversity (Galerucinae sensu lato, including Alticini contain about 1200 genera and 18000 species), and resulting problems of inadequate sample size. Discovery and proper documentation of generic diversity of flea beetles will contribute to resolution of their phylogentic relationships in the near future.

\section{Material and methods}

Beetle structures were studied under a Zeiss Stemi SV11 Apo microscope. The female genitalia were dissected and mounted into slides with Hoyer's medium, photos were taken with digital camera Nikon 5200D attached to the Zeiss Axiostar Plus microscope. Observations of the male genitalia and habitus were made with a Zeiss Discovery V20 microscope and digital images were taken with an AxioCam HRC digital camera attached to it. Scanning electron micrographs were taken with FEI Quanta 450. Morphological terminology follows Konstantinov (1998).

Abbreviations of collections:

IZCAS Institute of Zoology, Chinese Academy of Sciences, Beijing, China

USNM National Museum of Natural History, Washington DC, USA 


\section{Penghou new genus}

(Figs 1-25)

Body length: $1.90-2.20 \mathrm{~mm}$; body width (widest point of elytra): $0.80-1.10 \mathrm{~mm}$. Pronotum width to length: $1.08-$ 1.12. Width of elytra at base (in middle of humeral calli) to width of pronotum at base: 1.30-1.40.

Head, pronotum except base, ventral side of body, and femora dark brown to black with light bronzish tint. Elytral disc, basal part of pronotum, tibiae, tarsi, and antennae light brown. Elytral surface and frontal part of pronotum with sparse, erect hairs (Figs 1,2).
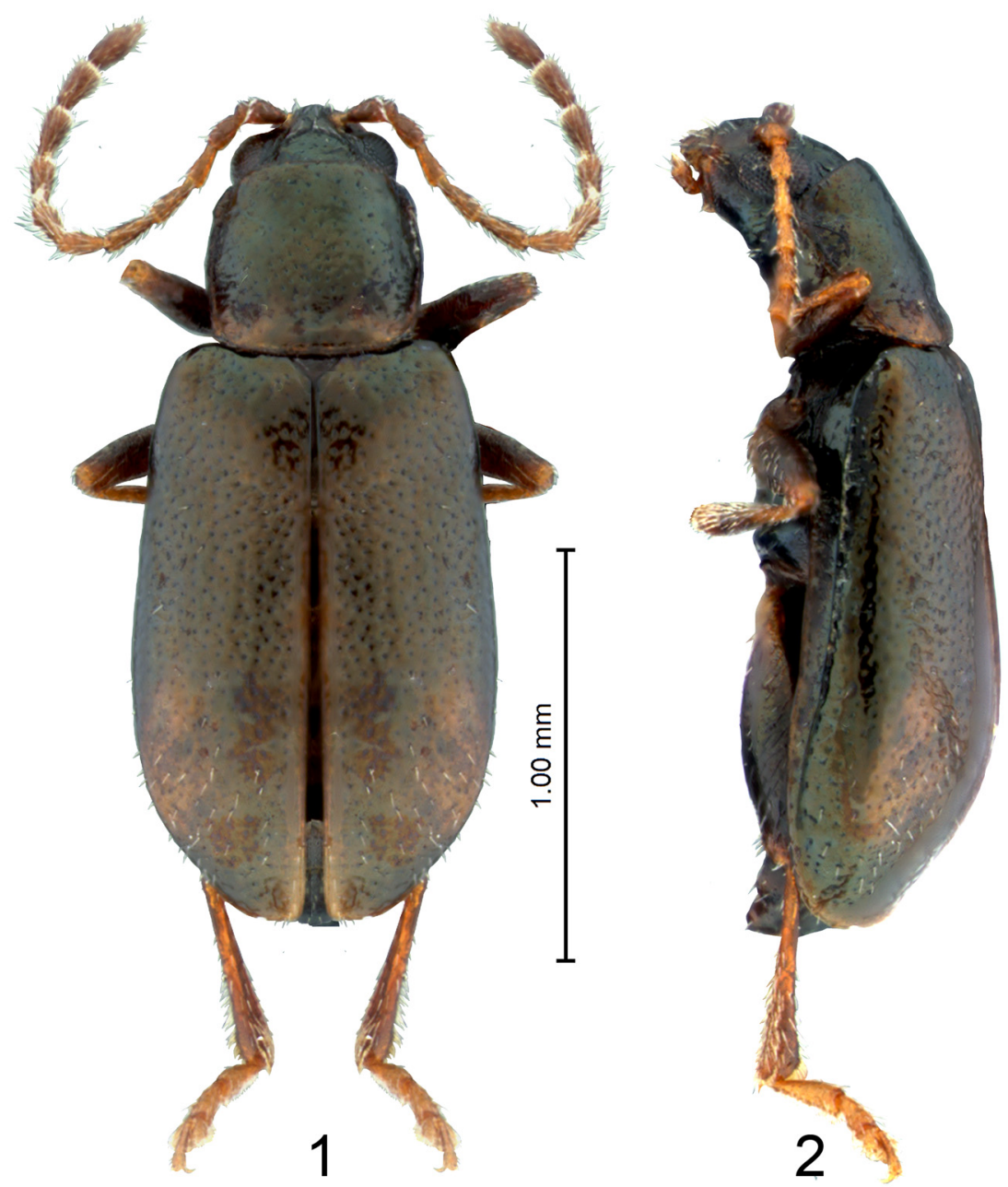

FIGURES 1, 2. Penghou yulongshan sp. n., 1-paratype, dorsal habitus; 2-paratype, lateral habitus.

Head (Figs 3,6) with midcranial and frontal sutures absent. Supraorbital sulcus shallow, sometimes consisting of few long and parallel wrinkles. Orbital sulcus and supracallinal sulci well developed. Supraantennal sulcus shallow, poorly developed. Supracallinal sulcus oblique and slightly convex. Midfrontal sulcus well developed, long; antennal calli completely separated. Suprafrontal and frontolateral sulci well developed. Antennal callus long, oblique, nearly trapezoidal, entering interantennal space. Surface of antennal callus above surface of vertex. Frontal ridge and vertex separated by antennal calli. Width of frontal ridge to width of antennal socket (counting surrounding ridges) $0.70-0.75$. Frontal ridge in lateral view moderately convex. Area below antennal socket concave. Orbit normally wide, nearly as wide as transverse diameter of antennal socket. Distance between eyes above antennal sockets to transverse diameter of eye in frontal view 3.25-3.32. Sides of head below eyes converging ventrally. Labrum flat, trapezoid, with 2 pairs of setae; anterior margin slightly emarginate. Apical maxillary palpomere conical (Fig. 5). Preapical maxillary palpomere much wider than apical palpomere. Antennal sockets situated below middle of eye. Antenna filiform, with 11 antennomeres. Length of antenna over pronotum reaching middle of elytron. 


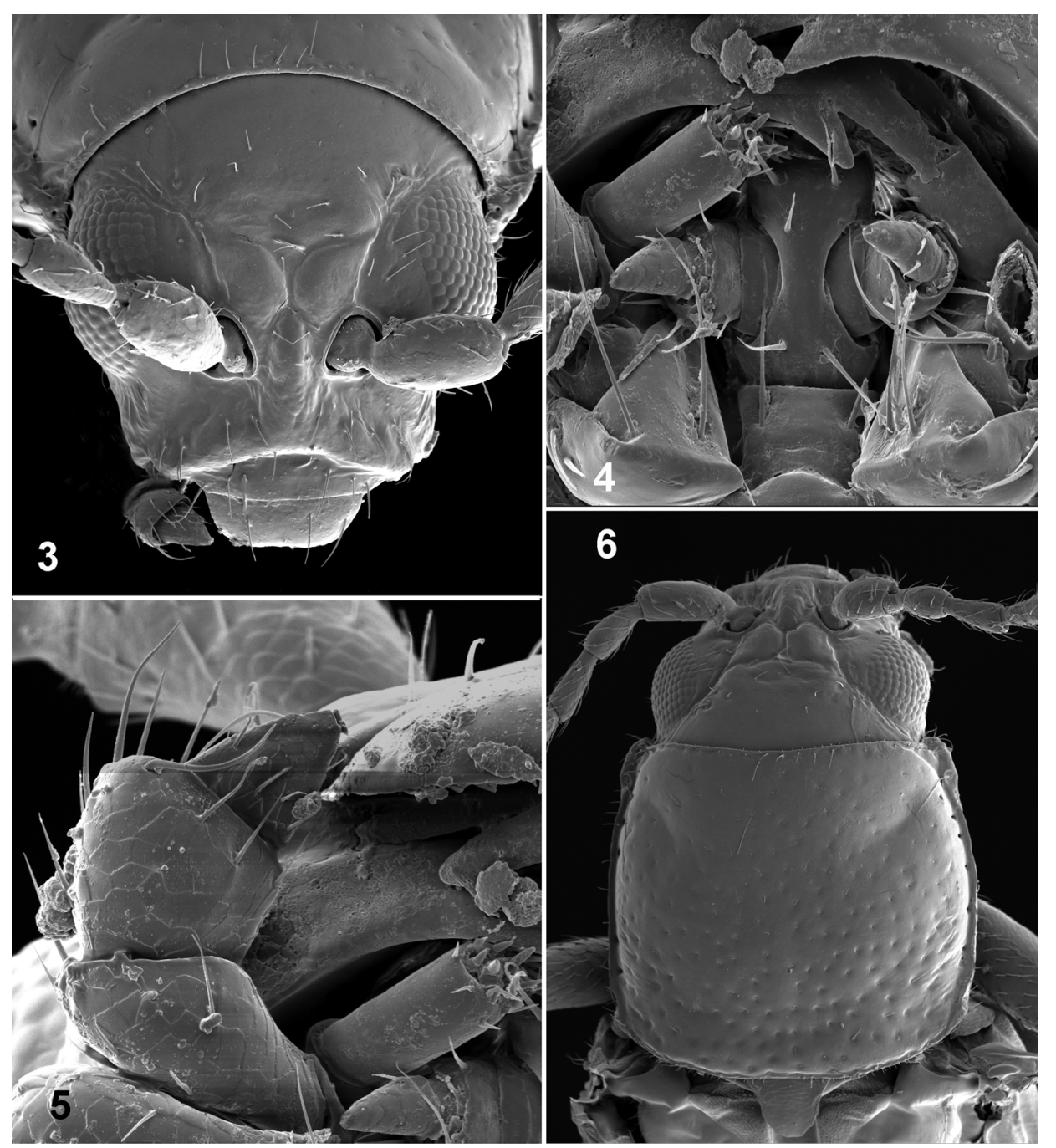

FIGURES 3-6. Penghou yulongshan sp. n., 3-head, frontal view; 4-mouth parts, ventral view; 5-maxilla; 6-pronotum.

Pronotum (Fig. 6) about as long as wide, with sides only slightly convex. Pronotal surface near base slightly transversely impressed, impression without distinct borders. Pronotal surface near apex with two oblique, shallow impressions forming in middle an even shallower impression. Pronotal base straight. Lateral margin of pronotum slightly explanate, with short setae. Anterolateral callosity relatively long, nearly parallel to lateral margin. Posterolateral callosity short, not protruding beyond lateral margin. Pronotal punctures larger and denser at base than at apex. A few short setae situated on apical margin and on basal margin near corners. Procoxal cavities open (Fig. 8). Intercoxal prosternal process thin, extends beyond procoxae, lateral sides concave, posterior end slightly widened and straight.

Scutellum present. Elytron (Fig. 15) with punctures confused, dorsal surface covered with sparse erected setae. Elytra at base wider than base of pronotum. Humeral calli well developed. Basal calli poorly developed with shallow impression posteriad. Epipleura (Fig. 17) oblique outwardly, gradually narrowing from base to apex, reaching end of side of elytron, but not apex. Width of epipleura in middle equal to width of metafemur at apex. Internal surface of elytron (Figs 16, 18-20) with 2 binding patches, spicules in middle of basal patch shovel shaped (Fig. 20), spicules on more distant patch ogival in shape, slightly bent anteriorly (Fig 19). Mesosternum (Fig. 8) without elevated projection in middle. Metasternum (Fig. 10) anteriorly without elevated projection in middle and not projecting forward hiding mesosternum. Metepisternum anteriorly wider than posteriorly.

Abdominal ventrites 1 and 2 not fused (Fig. 10). Abdominal ventrite 1 as long as ventrites 2, 3 and 4 together. Abdominal ventrite 5 longer than ventrites 4 and 3 together, evenly convex in female, in male obliquely cut on sides with lobe in middle. First abdominal ventrite beween coxae without longitudinal ridges, with apex narrowly truncate. Last visible tergite without longitudinal groove in middle. 


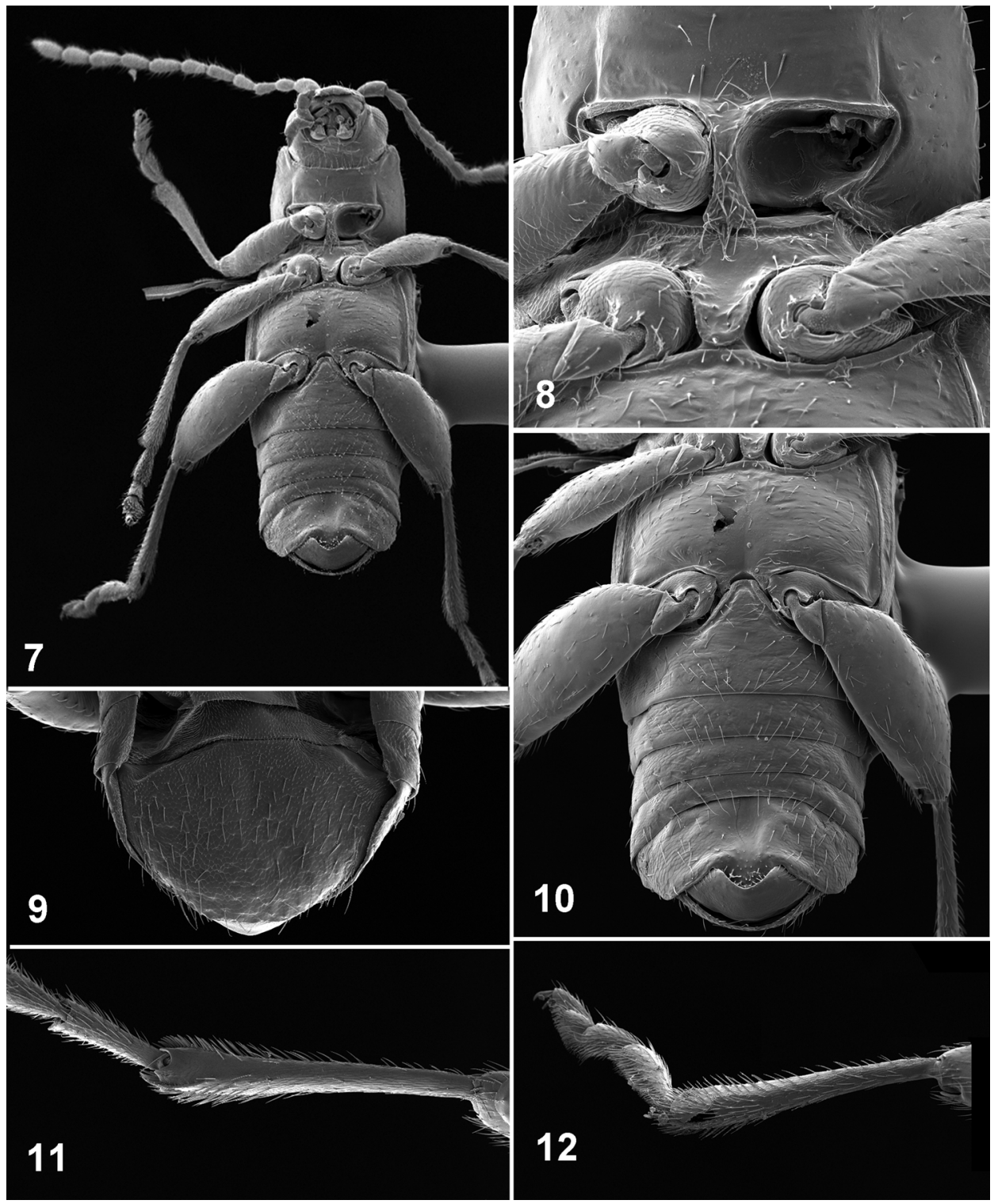

FIGURES 7-12. Penghou yulongshan sp. n., 7-paratype, ventral side; 8-pro- and mesosterna; 9 -last abdominal tergite; 10 - metasternum and abdominal ventrites; 11 - metatibia, dorsal view; 12 - metatibia lateral view.

Protibial and mesotibial spurs absent. Metatibia straight (Figs 7, 11, 12). Metatibia in crossection around its middle more or less cylindrical. Middle part of metatibia dorsally convex. Bristles present on lateral and mesal sides of metatibiae. Metatarsomere 1 attached to apex of metatibia. Apical spur of metatibia simple, much shorter than maximum width of metatibial tip, narrow, ending in one tooth, situated medially. Tarsus with tarsomere 3 round, wider than long, with small incision in middle. First metatarsomere relatively long, but shorter than those in Longitarsus Latreille, convex dorsally, flat ventrally. Claws slightly appendiculate (Fig. 13). Wing with generally reduced veins. Radial vein slender, rp-mp2 short (Fig. 21).

Median lobe of male genitalia in cross section somewhat oval (Fig. 25).

Spermatheca with distinct border between receptacle and pump. Receptacle longer than wide, much wider and longer than pump, straight. Spermathecal duct curved, without coils (Fig. 23). Vaginal palpi not fused medially, with length many times greater than width (Fig. 22). Tignum with narrow base and dilated apex (Fig. 24).

Etymology. We named the genus after the Pénghoú (), a tree spirit from Chinese folklore. The name is masculine.

Type species. Penghou yulongshan Ruan, Konstantinov, Prathapan, Ge, Yang, new species.

Distribution. China (Yunnan province.).

Host plant. Unknown. 

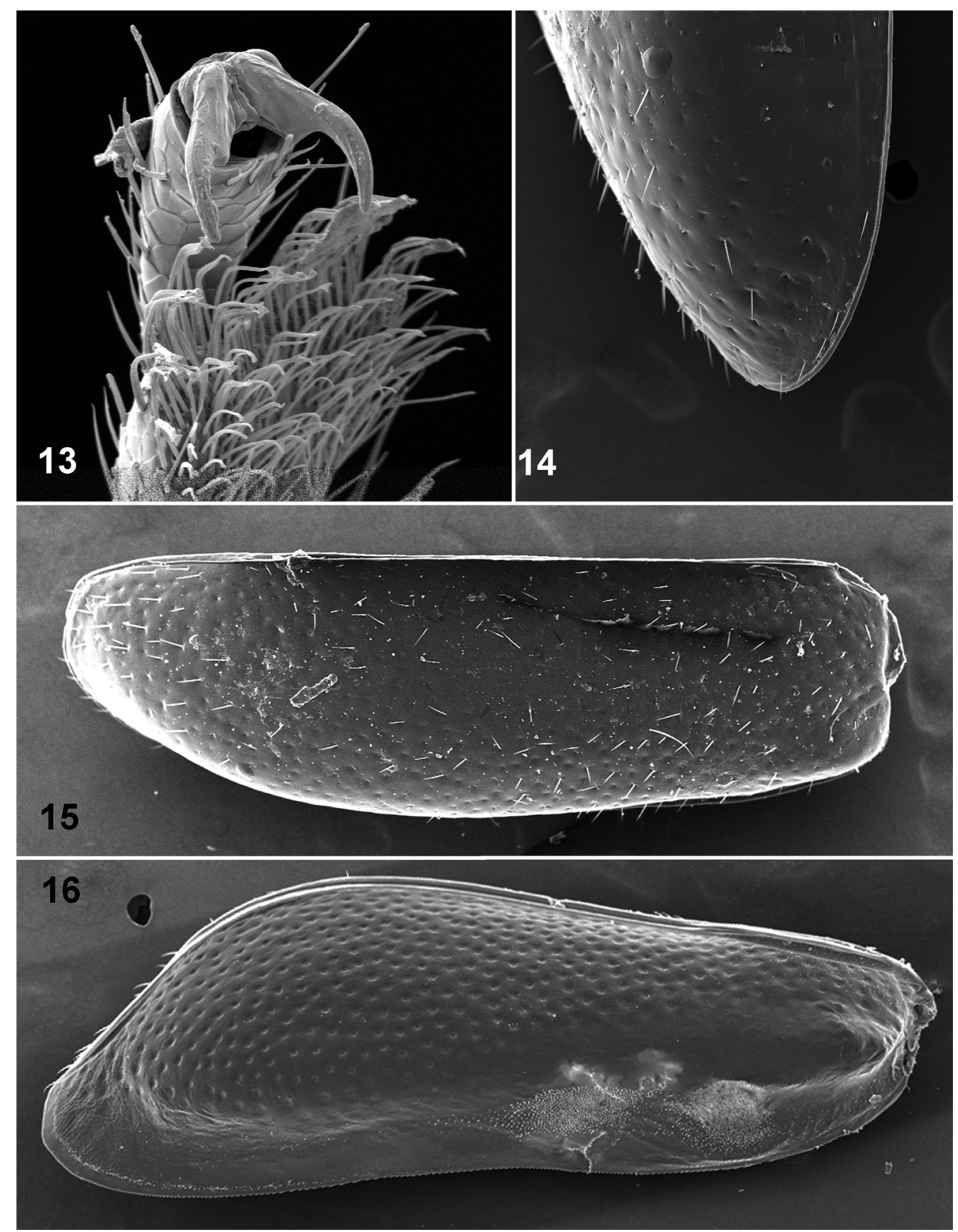

FIGURES 13-16. Penghou yulongshan sp. n., 13-tarsal claws; 14 - elytral apex; 15-right elytron, dorsal view; 16-left elytron, ventral view.

Remarks. Penghou is markedly different from all known genera of Chinese and broadly Oriental flea beetles. However, based on the general shape of the beetle body, setose elytra and general shape of the legs, Penghou is similar to Hespera and related genera (Hesperomorpha Ogloblin and Taiwanohespera Kimoto), Laotzeus Chen, Luperomorpha, Mandarella Duvivier, Omeiana Chen, and Stenoluperus Ogloblin. Penghou may be easily distinguished from the latter genera based on the following characters: smaller body size (maximum-2.2 mm, while average body size of Hespera-Stenoluperus is $3.6 \mathrm{~mm}$ ); pronotum clearly elongate, about as long as wide, pronotum in Hespera-Stenoluperus generally much wider than long; pronotum with weak antebasal transverse impression and two oblique impression near apex, pronotum in Hespera-Stenoluperus (except for Laotzeus) lacks impressions, respectively; anterolateral callosity of pronotum elongate, barely extending beyond pronotal margin, the callosity is rounded, extending far beyond pronotal margin in Hespera-Stenoluperus (except some species of Luperomorpha); supracallinal sulci oblique, they are generally perpendicular to mid of the head in HesperaStenoluperus. 


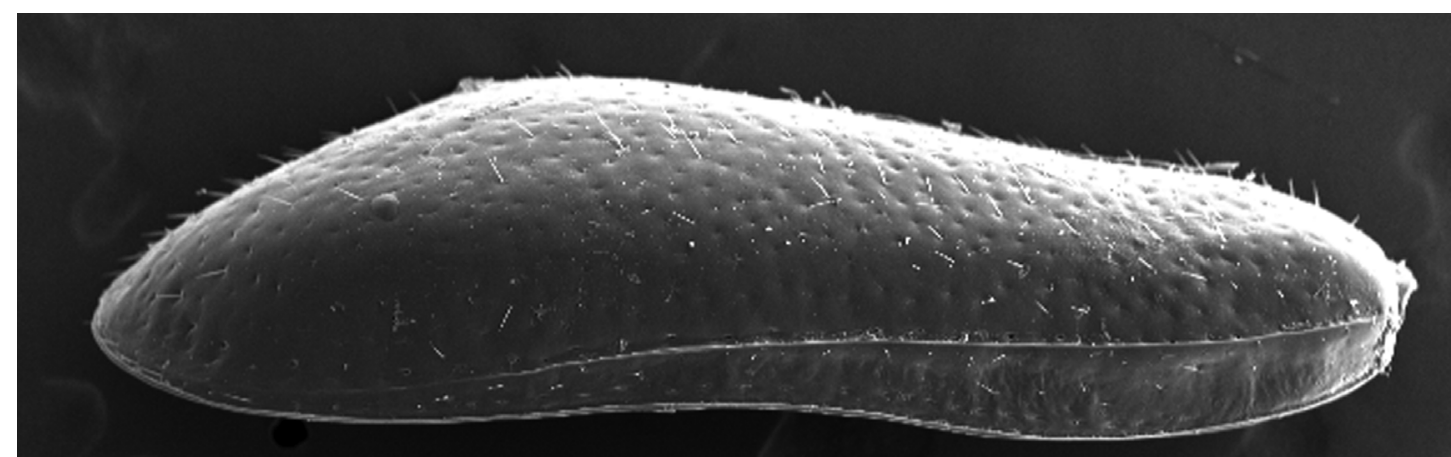

17
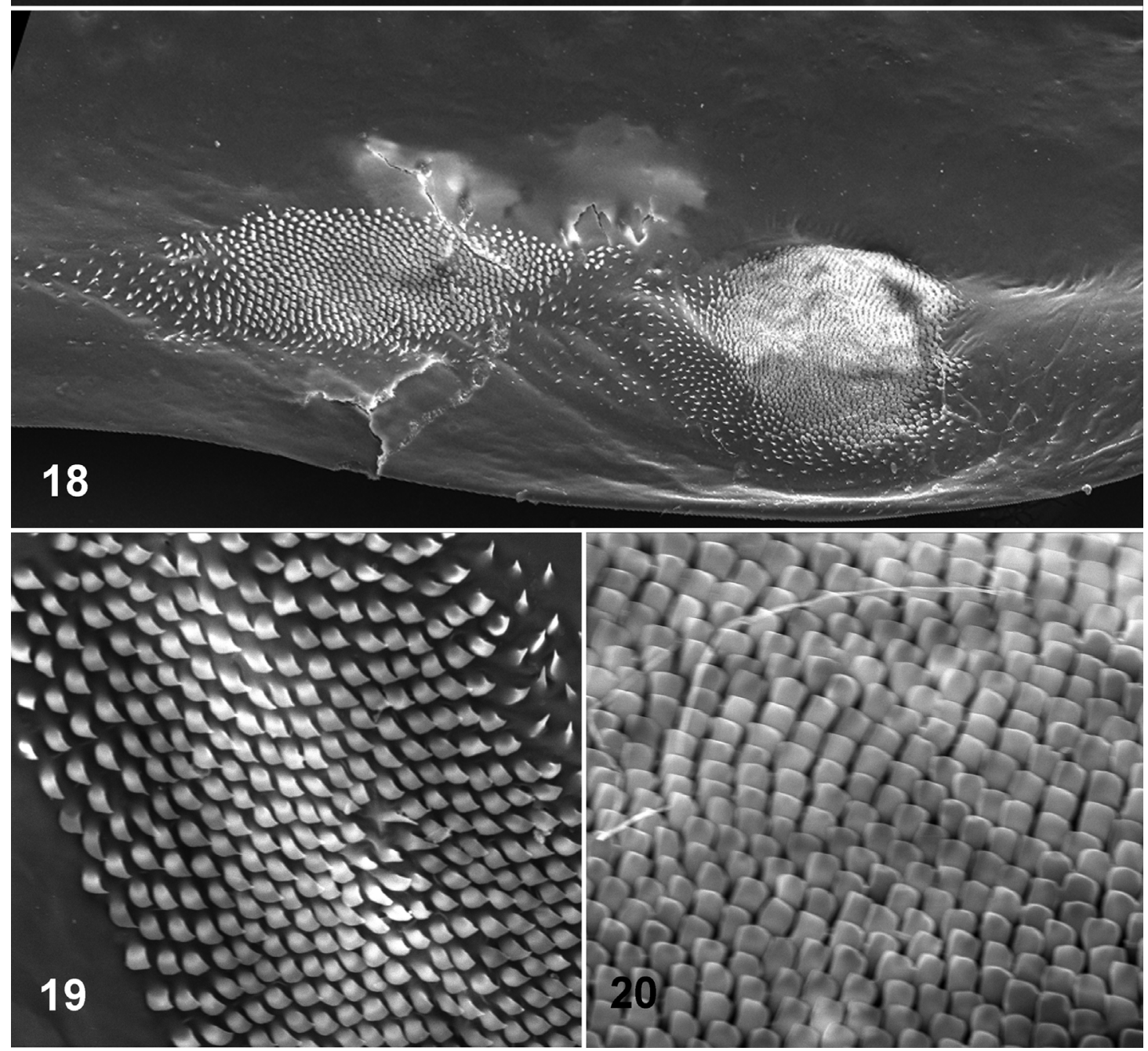

FIGURES 17-20. Penghou yulongshan sp. n., 17—right elytron, lateral view; 18—elytron binding patches; 19—spicules on distant binding patch; 20-spicules on basal binding patch.

\section{Penghou yulongshan new species}

(Figs 1-25)

Body length: $1.90-2.20 \mathrm{~mm}$; body width: $0.80-1.10 \mathrm{~mm}$. Ratio of pronotum width at base to width at apex: 1.00 1.05. Elytra length (along suture) to width of both (maximum): 1.59-1.63. Length of elytron to length of pronotum: 2.70-2.90. Abdomen length to height of the body (in lateral view including metasternum): 2.65-2.72. 
Head, pronotum except base, lateral sides of elytra, ventral side of body, basal antennomere, and femora dark brown to black with light bronzish tint. Elytral disc, basal part of pronotum, tibae, and tarsi, and antennomere second to seventh light brown. Elytral surface and frontal part of pronotum with sparse, erect hairs.

Vertex with shallow, oblique grooves above antennal calli. Surface of vertex covered with mostly transverse wrinkles and with few shallow punctures. Orbit with 2 setiferous punctures. Supraorbital pore barely recognized. Distance between antennal sockets to transverse diameter of one antennal socket 1.25-1.30.

Antennomere 1 shorter than next two combined. Antennomere 2 about as long but wider than antennomere 3 , shorter than 4 . Antennomere 5 about as long as antennomeres 4 and 6 separately. Lenght to width of antennomere 9: $1.75-1.80 ; 10: 1.62-1.68$; and $11: 2.25-2.35$.

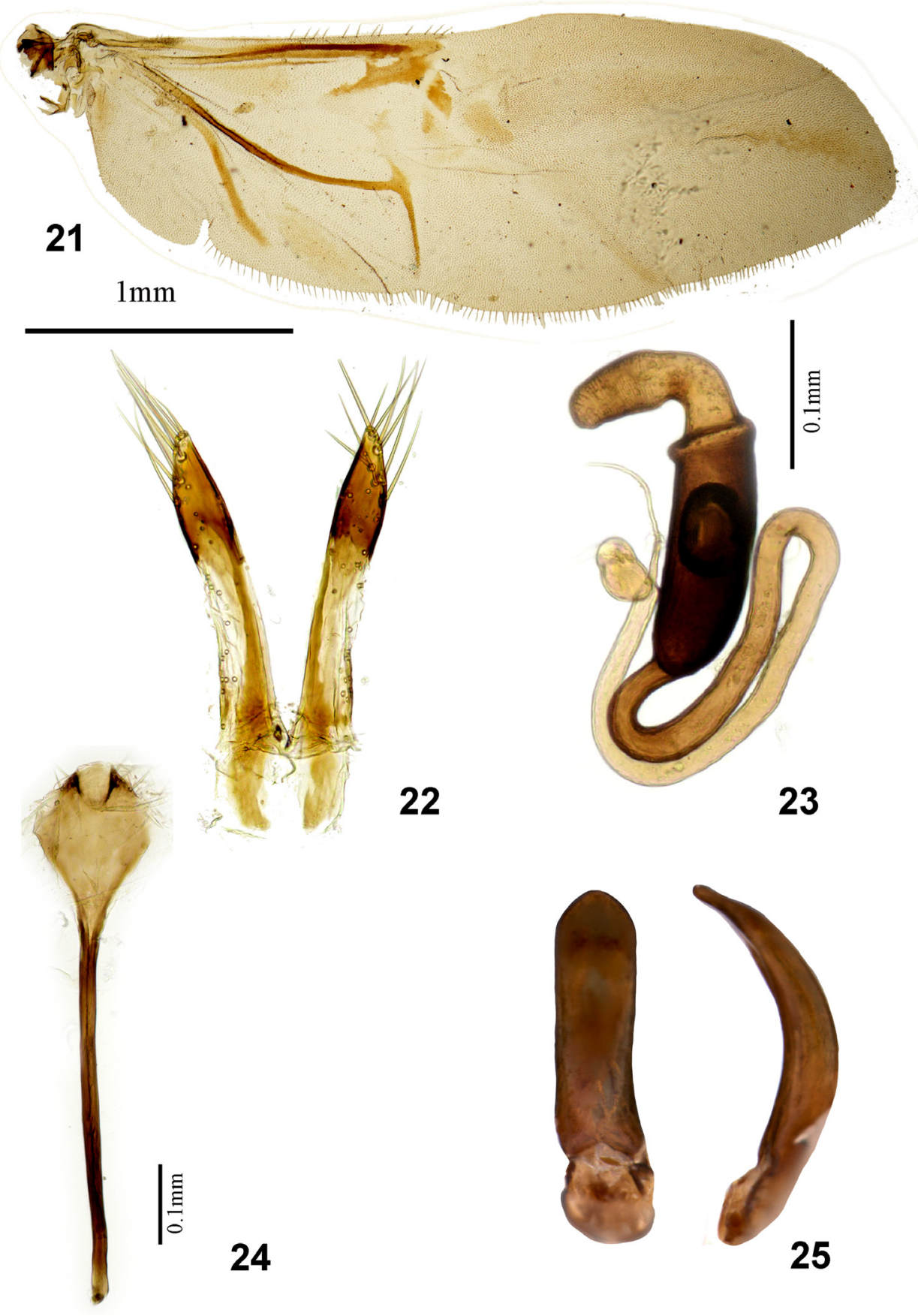

FIGURES 21-25. Penghou yulongshan sp. n., 21-wing; 22-vaginal palpi; 23-spermathca; 24 -tignum; 25-median lobe of aedeagus, ventral and lateral views. 
Pronotal surface covered with relatively coarse punctures, distance between them about as great or greater than their diameter. Punctures on sides form relatively deep, oblique wrinkles.

Elytral punctures on disc about as large and dense as pronotal punctures, smaller sparser and shallower on sides and apex.

Length (not counting trochanter) to maximum width of metafemur 2.35-2.45. Length to width of metatibia in lateral view 5.60-5.70. Width of metatibia at base to width at apex in dorsal view 0.44-0.45. Lenght of metatibia to lenght of first metatarsomere 2.80-2.85. Length of metafumur to metatibia 1.15-1.20. Apical spur of metatibia simple, narrow, ending in one tooth, situated medially. First protarsomere of males about as wide and long as in females. First protarsomere of male, length to width ratio (in dorsal view): 1.62-1.70. Length of first protarsomere to length of second protarsomere: $1.40-1.45$. Width of first protarsomere to width of second protarsomere: 1.12 1.17. First metatarsomere of male, length to width ratio (in dorsal view): 3.10-3.12. Length of first metatarsomere to length of second metatarsomere: $1.50-1.60$. Width of first metatarsomere to width of second metarsomere: 0.97 1.02. Length of fourth metatarsomere to length of third metatarsomere: 1.80-1.90.

Median lobe of male genitalia relatively short and wide, with apex narrowing broadly, lacking denticle. Ventral surface with relatively narrow groove, widening abruptly in apical one third.

Spermathecal receptacle nearly cylindrical with straight inner side and slightly curved outer side. Border between receptacle and pump making a "lip" on internal side. Spermathecal duct long, making 3 turns in a single plain. Vaginal palpi separated medially, with apex gradually convex laterally and nearly straight medially, bearing about 9 long setae. Posterior end of tignum relatively well sclerotised, forming two highly sclerotized, long teeth at the end.

Etymology. This species is named after the mountain region in Yunnan, Yulongshan where it was collected.

Holotype. male: 1) China, Yunnan, Lijiang, 29.V. 2002, Yulongshan, Black River, 2800m, N27 $08^{\prime} 46^{\prime \prime}$ E100 $15^{\prime} 03^{\prime \prime}$, leg. A. Konstantinov \& M. Volkovitsh; 2) of; 3) Holotype; 4) Penghou yulongshan n. sp. des. Ruan et al. 2014 (IZCAS).

Paratypes. Male and female: 1) China, Yunnan, 30.V.2002, 20km N Lijiang Yulongshan, 3406m, dry river, N2705'39"E100¹3'45", leg. A.Konstantinov \&M. Volkovitsh; 2) Paratype Penghou yulongshan new species, des. Ruan et al. 2014 (2 USNM). Male: 1) China, Yunnan, 32km N. Lijiang, 02.VI.2002, Yak Meadow, 3600m N27 $10^{\prime} 11^{\prime \prime E} 100^{\circ} 14^{\prime} 55^{\prime \prime}$, leg. A.Konstantinov \&M. Volkovitsh; 2) Paratype Penghou yulongshan new species, des. Ruan et al. 2014 (USNM). Male: 1) China, Yunnan, Lijiang, 29.V.2002, Yulongshan, Black River 2800m N27 $08^{\prime} 46^{\prime E} 100^{\circ} 15^{\prime} 03^{\prime \prime}$, leg. A.Konstantinov \&M. Volkovitsh; 2) Paratype Penghou yulongshan n. sp., des. Ruan et al. 2014 (USNM).

Distribution. China (Yunnan province.).

Host plant. Unknown.

\section{Acknowledgements}

We are grateful to M. Volkovitsh (Zoological Institute, Russian Academy of Sciences, St. Petersburg, Russia) for his friendship and camaraderie during collecting trip in China in 2002. Mention of trade names or commercial products in this publication is solely for the purpose of providing specific information and does not imply recommendation or endorsement by the USDA; USDA is an equal opportunity provider and employer. This research was supported by grants from the National Science Foundation of China to Xingke Yang (PI, Grant No. 31372239) and the National Science Fund for Fostering Talents in Basic Research (Special Subjects in Animal Taxonomy, NSFC-J1210002).

\section{Literature cited}

Ge, D., Gómez-Zurita, J., Chesters, D., Yang, X. \& Vogler, A. (2012) Suprageneric systematics of flea beetles (Chrysomelidae: Alticinae). Molecular Phylogenetic and Evolution, 62, 793-805. http://dx.doi.org/10.1016/j.ympev.2011.11.028

Konstantinov, A.S. (1998) Revision of the Palearctic species of Aphthona Chevrolat and cladistic classification of the Aphthonini (Coleoptera: Chrysomelidae: Alticinae). Memoirs on Entomology International. Vol. 11. Associated 
Publishers, Gainesville, 429 pp.

Konstantinov, A.S., Baselga, A., Grebennikov, V.V., Prena, J. \& Lingafelter, S.W. (2011) Revision of the Palearctic Chaetocnema species (Coleoptera: Chrysomelidae: Galerucinae: Alticini). Pensoft, Sofia-Moscow, 363 pp.

Konstantinov, A.S., Chamorro, M.L., Prathapan, K.D., Ge, S. \& Yang, X. (2013) Moss-inhabiting flea beetles (Coleoptera: Chrysomelidae: Galerucinae: Alticini) with description of a new genus from Cangshan, China. Journal of Natural History, 47 (37-38), 2459-2477.

http://dx.doi.org/10.1080/00222933.2012.763068

Lopatin, I.K. \& Konstantinov, A.S. (2009) New genera and species of leaf beetles (Coleoptera: Chrysomelidae) from China and South Korea. Zootaxa, 2083, 1-18.

Ruan, Y., Konstantinov, A.S., Ge, S. \& Yang, X. (2014) Revision of the Chaetocnema picipes species-group (Coleoptera, Chrysomelidae, Galerucinae, Alticini) in China, with descriptions of three new species. Zookeys, 387, 11-32. http://dx.doi.org/10.3897/zookeys.387.6672

Sprecher-Uebersax, E., Konstantinov, A.S., Prathapan, K.D. \& Doeberl, M. (2009) Revision of the genus Benedictus Scherer (Insecta: Coleoptera: Chrysomelidae: Galerucinae). In: Hartmann, M. \& Weipert, J. (Eds.), Biodiversity and Natural Heritage of the Himalaya. Vol. 3. Verein der Freunde \& Förderer des Naturkundemuseums Erfurt e. V., Erfurt, pp. 367406. 